\title{
A REVIEW ON EFFECT OF VARIOUS PARAMETERS ON CUTTING TOOL IN ORTHOGONAL METAL CUTTING PROCESS
}

\author{
Sandeep B. Survase ${ }^{1}$, P. D. Darade ${ }^{2}$, Ganesh K. Lamdhade ${ }^{3}$ \\ ${ }^{I}$ PG Student, Department of Mechanical Engineering, Sinhgad Institute of Technology \& Science, Maharashtra, India \\ ${ }^{2}$ Assistant Professor, Department of Mechanical Engineering, Sinhgad Institute of Technology \& Science, \\ Maharashtra, India \\ ${ }^{3}$ Assistant Professor, Department of Mechanical Engineering, Vishwkarma Institute of Information Technology, \\ Maharashtra, India
}

\begin{abstract}
In recent years there is great progress in the field of tool design. Tool is an important factor for machinability process. In the metal cutting process various cutting parameters affecting on the cutting tool. The various parameters include as cutting speed, feed rate, depth of cut, rake angle. The effect of these parameters on the cutting forces, tool temperature, and surface roughness studied. This helps in evaluating the tool life and tool wear. This effect of parameters on tool is important for efficient machining and machining conditions. The paper also covers the effect of cutting parameters on the chip formation and residual stresses produced during cutting process.
\end{abstract}

Keywords: Cutting parameters, orthogonal, cutting process, cutting tool.

\section{INTRODUCTION}

There are two types of metal cutting as orthogonal cutting and oblique cutting. In orthogonal cutting, the cutting edge of the tool is at right angles to the direction of the relative motion between the tool and the workpiece. In oblique cutting, the cutting edge is inclined but not perpendicular to the direction of the relative motion between the tool and workpiece. During the cutting process the various forces acting on the tool. The study of effect of these forces is necessary for the qualitative analysis. The cutting parameters include the cutting speed, feed and depth of cut.

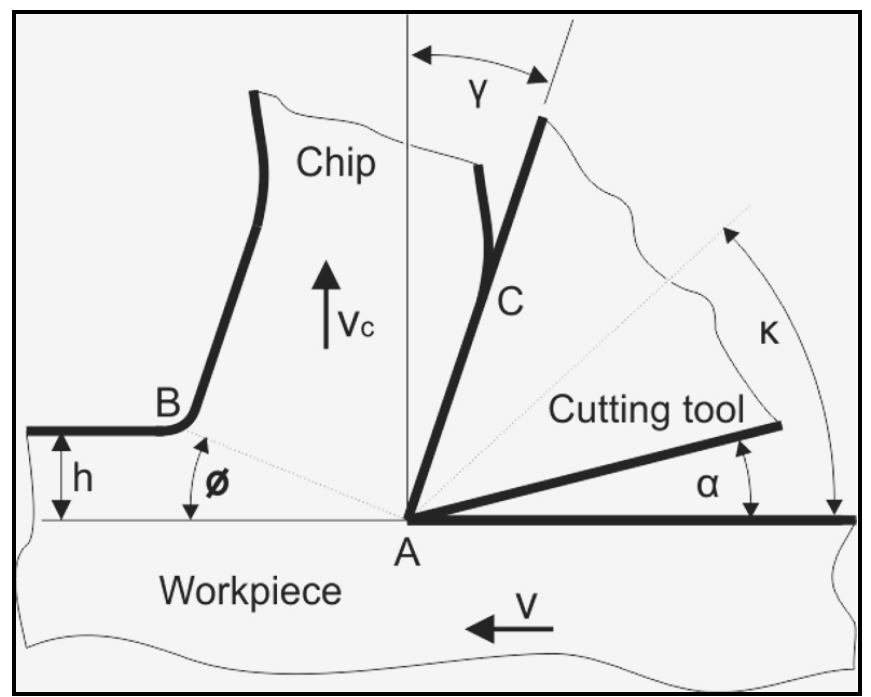

Fig. 1 The classical orthogonal cutting model [7]

The machinability is influenced by the tool variables, machine variables, cutting conditions and work material variables. These parameters may create failure of tool, poor surface finish, sudden increase in forces, increase in temperature and stresses. The tool life and tool wear also depends on these parameters. For the optimum machining, these parameters should be in proper consideration like nature of cut to be made, feed, depth of cut, speed. [16]

\section{LITERATURE REVIEW}

Lei Wan et al. [1], investigated the effect of different cutting tool edge geometries by using finite element simulation method. The P20 used as a workpiece material for orthogonal machining and carbide tool with different angles and lengths with different cutting speeds. The arbitrary Lagrangian-Eulerian (ALE) approach was used for simulation in ABAQUS/Explicit. The results show that the tool edge geometries influence on the chip removal process with less significantly and little effect on the machining force when the cutting speed reaches a very high level. The cutting forces increases with increase in chamfer angle and decreases with increase in cutting speed.

Awadhesh Pal et al. [2], experimentally investigated the effect of workpiece hardness and cutting parameters on the different responses which was analyzed by performing analysis of variance (ANOVA) technique. The AISI 4340 steel used as a material and $\mathrm{TiC}$ mixed alumina ceramic tool used for soft and hard turning. From the experiment they observed that all the components of cutting forces increases with the increase in depth of cut and the magnitude of the cutting forces increases with the increase in workpiece hardness. The results also show that surface roughness decreases with increase in hardness level of workpiece and average value of the chip-tool interface temperature increases with increase in cutting speed. 
Sudhansu Ranjan Das et al. [3], experimentally investigated the effect of cutting speed, feed and depth of cut on the cutting force and surface roughness. The AISI 52100 bearing steel used as a material and CNB tool used for an experiment. The analysis of variance (ANOVA) technique was used for identifying the factors significantly affecting the cutting force and surface roughness. Their results show that the feed rate and cutting speed strongly influence on the surface roughness. Also the cutting force increases with the increase in feed rate and depth of cut and decreases with cutting speed.

Atul P. Kulkarni et al. [4], experimentally investigated the effects of machining parameters on the surface finish, cutting force, tool wear, chip thickness and tool life. The AISI 304 austenitic stainless steel used as a workpiece and AlTiCrN coated insert produced by High Power Pulsed Magnetron Sputtering (HPPMS) used for dry turning. The experiment was carried out at different cutting speed and feed with constant depth of cut. The results show that the surface roughness value increases with increase in feed and low at the high cutting speed. The flank wear was prominently affected by cutting speed and feed.

$\mathrm{H}$ Aouici et al. [5], experimentally investigated the effect of cutting conditions on surface roughness and cutting forces in hard turning of X38CrMoV5-1 with CBN tool. The results shows that the effects of cutting speed on surface roughness and on cutting forces at various feed rates and also show that the analysis of variance(ANOVA) of the data with the surface roughness parameters and cutting forces components. They concluded that the depth of cut has a maximum effect on the cutting force component as compared to the feed rate and cutting speed.

K. Khalili and M. Danesh [6], investigated the effect of cutting tool geometry on morphology of flank wear land in turning of low carbon steel. The image processing technique and Response Surface Method used for investigation this effect. For experiment the cutting speed, feed rate and depth of cut kept constant. The results show that the area of flank wear land decreases with an increase of both relief angle and the rake angle and increases with the increase of cutting edge angle for lower values of the rake angle.

M. Cebron et al. [7], experimentally find out the effect of cutting on surface hardness and residual stresses for $12 \mathrm{Mn}$ austenitic steel. The results show the material hardening and residual stresses induced during machining for highlyhardening $12 \mathrm{Mn}$ austenitic steel. As the feed rate increases it lowers the hardness of the material on the contact face of the chip. The residual stresses increases with increase in feed rate and cutting speed.

Nicoleta Lungu and Marian BORZAN [8], performed the finite element simulation to study the effect of cutting speed and feed rate on tool geometry, temperature and cutting forces. The AISI 1045 carbon steel used as a workpiece material and tungsten carbide coated with a TiCN layer used as a tool. The Deform 2D machining software used for finite element simulation. The results shows that the temperature value increases with the increase in cutting speed but at that time the value of cutting forces decreases and cutting forces increases with increase in feed rate.

Rodrigues L. L. R. et al. [9], conducted experiment to investigate the effect of cutting parameters on surface roughness and cutting force in turning mild steel by using high speed steel cutting tool. The analysis of variance (ANOVA) was used for the effect of cutting parameters. The results shows that the cutting force increases linearly with the increase in depth of cut and surface roughness was influenced by feed rate and the interaction between speed and feed. They concluded that the feed and depth of cut has significant effect on cutting force but cutting speed and depth of cut had no significant effect on surface roughness.

S. Ben Salem et al. [10], investigated the effect of cutting parameters on chip formation in orthogonal cutting. The high alloyed steel (type EN X160CrMoV12, AISI D2) used as a material. The experiment was performed at different cutting speed and feed rate. As the feed rate increased the chip gets shape of the saw-tooth chip. As the cutting speed increases the chip becomes relatively ductile.

Irfan Ucun et al. [11], developed a finite element based computational model to determine the effect of tool geometry on the cutting force and temperature. The AISI 1045 carbon steel were used as a material with ceramic insert having different edge geometry for an experiment. They compered the results obtained by experiments and finite element simulation of the cutting forces at different cutting speed and feed rate. The results shows that the effect of the chamfer angle and feed rate on cutting forces also effect of the chamfer length and feed rate on cutting forces. They concluded that the increase in cutting force and thrust force depends on increasing chamfer angle and chamfer length. They also concluded that the chamfer angle has more significant effect on the cutting temperature depending on the increase at the cutting speed and the maximum temperature occurring on the cutting tool occurs at different points in line with the variation at the chamfer length.

Satyanarayana Kosaraju et al. [12], experimentally investigated the effect of rake angle and feed rate on cutting forces in an orthogonal turning process. The high speed steel cutting tools were used for machining EN8 hollow cylindrical workpiece. An experiment were performed at different rake angles and feed rate with constant speed and depth of cut. The experimental result shows that the feed force was greater than the tangential force and the longitudinal force was least in magnitude irrespective of the tool rake angle. From an experiment they conclude that the cutting forces decreases with increase in rake angle and the cutting forces increases continuously with an increase in feed for all rake angles.

Wan Masrurah Bt Hairudin and Mokhtar B Awang [13], developed a fully coupled thermo mechanical finite element model for simulating the orthogonal cutting in cutting 
process. The simulation was performed at three different tool rake angles and tool edge radius. An Arbitrary Lagrangian-Eulerian method was used for thermo mechanical modelling. The results show that with increase in rake angle the stress on the workpiece decreased also temperature significantly increased when tool rake angle was decreased.

E. D. Derakhshan and A. A. Akbari [14], investigated the effects of workpice hardness and cutting speed on surface roughness of steel bars of AISI 4140. The experiment was conducted on hard turning of hardened alloyed steel AISI 4140 with hardness of 45-65 HRC at various cutting speeds. They concluded that the best surface quality in hard turning of 55 HRC workpiece with CB50 tool at $2500 \mathrm{rpm}$ speed. They also concluded that the increase in cutting speed had a tremendous effect of resulting surface roughness.

Jaharah A. G. et al. [15], presented the simulation work of turning process of AISI 1045 and carbide tool by using finite element method. The Deform-3D software was used for simulation of orthogonal metal cutting process. The simulation process was carried out by changing the rake angle, clearance angle and cutting speed parameters. The results shows that the effect of tool geometries on the effective stress and temperature at various combinations of rake angle and clearance angle. By this analysis it was found that the temperature increases when the negative rake angle tool used. They also shows that the effect of increasing of cutting speed on the effective stress and temperature. The authors concluded that if cutting speed increases then the effective stress reduced.

\section{SUMMARY}

In this paper, the review on effect of various parameters on orthogonal metal cutting process studied. It is observed that the cutting parameters have effect on the cutting tool. The cutting geometries have effect on the chip removal process. The cutting parameters have directly effect on the efficient machining process. The cutting parameters have effect on the cutting forces, tool temperature, surface roughness, residual stresses, tool life and tool wear.

The cutting forces increases with the increase in chamfer angle, feed rate, depth of cut and decreases with increase in cutting speed, rake angle of the tool. The surface roughness value decreases with increase in cutting speed, hardness level of workpiece and increases with increase in feed. The temperature value of tool increases with increase in cutting speed. It is observed that the most of the existing researchers not considered all parameters effecting on the cutting tool. Hence in order to fill this gap future research studies may be conducted on the effect of all these parameters on the cutting tool.

\section{ACKNOWLEDGEMENTS}

I am very thankful to my project guide Prof. P. D. Darade, Assistant Professor, Mechanical Engineering Department, Sinhgad Institute of Technology and Science, Pune and
Prof. Ganesh K. Lamdhade, Assistant Professor, Vishwakarma Institute of Information Technology, Pune, for his continuous support and encouragement in completing this work.

\section{REFERENCES}

[1]. Lei Wan, Dazhong Wang, Yayun Gao, Investigation on the effects of different tool edge geometries in the finite element simulation of machining, Strojniski vestnik Journal of mechanical engineering, 61(3), 2015, pp.157-166. [2]. Awadhesh Pal, S. K. Choudhury, Satish Chinchanikar, Machinability assessment through experimental investigation during hard and soft turning of hardened steel, Procedia Material Science, 6, 2014, pp. 80-91.

[3]. Sudhansu Rajan Das, Debabrata Dhupal, Amaresh Kumar, Experimental investigation on cutting force and surface roughness in machining of hardened AISI 52100 steel using CBN tool, $5^{\text {th }}$ International \& $26^{\text {th }}$ All India Manufacturing Technology, Design and research conference, 2014, pp. 336(1)-336(6).

[4]. Atul P. Kulkarni, Girish G. Joshi, Vikas G. Sargade, Dry turning of AISI 304 austenitic stainless steel using AlTiCrN coated insert produced by HPPMS technique, Procedia Engineering, 64, 2013, pp.737-746.

[5]. H Aouici, M A Yallese, A Belbah, M F Ameur, M Elbah, Experimental investigation of cutting parameters influence on surface roughness and cutting forces in hard turning of X38CrMoV5-1 with CBN tool, Sadhana, 38(3), 2013, pp. 429-445.

[6]. K. Khalili, M. Danesh, Effect of cutting tool geometry on morphology of flank wear land in turning of low carbon steels, Reasearch Journal of Applied Sciences, Engineering and Technology, 6(20), 2013, pp. 3798-3807.

[7]. M. Cebron, F. Kosel, J. Kopac, Effect of cutting on surface hardness and residual stresses for $12 \mathrm{Mn}$ austenitic steel, Journal of Achievements in Materials and Manufacturing Engineering 55/1 (2012) 80-89.

[8]. Nicoleta LUNGU, Marian BORZAN, Effect of cutting speed and feed rate on tool geometry, temperature and cutting forces in machining AISI 1045 carbon steel using FEM simulation, Proceedings in Manufacturing Systems, 7(4), 2012, pp. 245-252.

[9]. Rodrigues L.L.R., Kantharaj A.N., Kanthraj B., Freitas W. R. C., Murthy B.R.N., Effect of cutting parameters on surface roughness and cutting force in turning mild steel, Research Journal of Recent Sciences, 1(10), 2012, pp. 1926.

[10]. S. Ben Salem, E. Bayraktar, M. Boujelbene, D. Katundi, Effect of cutting parameters on chip formation in orthogonal cutting, Journal of Achievements in Materials and Manufacturing Engineering 50/1 (2012) 7-17.

[11]. Irfan Ucun, Kubilay Aslantas, Ismail Ucun, Finite element modelling of machining of AISI 1045 with ceramic cutting tool, JoMFT, 4(1/2), 2011, pp.1-17.

[12]. Satyanarayana Kosaraju, VenuGopal Anne, VenkateshwaraRao Ghanta, International Conference on Trends in Mechanical and Industrial Engineering, 2011, pp. 150-154. 
[13]. Wan Masrurah Bt Hairudin, Mokhtar B Awang, Thermo mechanical modelling of turning process using an Arbitrary Lagrangian-Eulerian method, IEEE, 2011, pp. 1-6. [14]. E. D. Derakhshan, A. A. Akbari, Experimental investigation on the effect of workpiece hardness and cutting speed on surface roughness in hard turning with CBN tools, Proceedings of World Congress on Engineering, 2, 2009, pp. 1-4.

[15]. Jaharah A. G., Hendri Y., Che Hassan C. H., Ramli R., Yaakob Z., Simulation of turning process of AISI 1045 and carbide tool using finite element method, Proceedings of the $7^{\text {th }}$ WSEAS International conference on Computational Intelligence, Man-Machine Systems and Cybernetics, 2008, pp. 152-156.

[16]. R. K. Jain, Production Technology, $16^{\text {th }}$ ed., Khanna Publishers, India, pp. 1180-1203.

\section{BIOGRAPHIES}

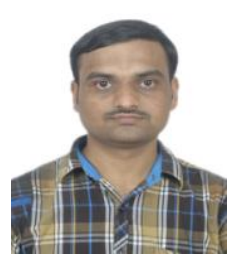

Mr. Sandeep B. Survase, have completed B.E. (Mechanical Engineering) with distinction from Sinhgad Institute of Technology \& Science, Pune. Presently pursuing M.E. (Design Engineering) from University of Pune.

Email-id: survasesbs@gmail.com

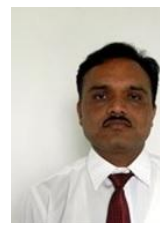

Prof. P. D. Darade, he is an Assistant Professor in department of mechanical engineering, Sinhgad Institute of Technology \& Science, Pune.

Email-id: daradepd@gmail.com

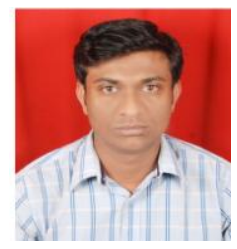

Prof. Ganesh K. Lamdhade, he is an Assistant Professor in department of mechanical engineering, Vishwakarma Institute of Information Technology, Pune.

Email-id: ganesh_lamdhade@yahoo.com 